\title{
APLICAÇÃO DO PROGRAMA 5S EM UMA MICROEMPRESA DE CONFECÇÃO
}

\section{Renan Nora Ferreira da Costa ${ }^{1}$, José Salvador da Motta Reis ${ }^{2}$, José Glênio Medeiros de Barros ${ }^{1}$, Otávio José de Oliveira ${ }^{2}$, Nilo Antonio de Souza Sampaio ${ }^{1}$}

${ }^{1}$ Universidade do Estado do Rio de Janeiro / Faculdade de Tecnologia, Rod. Pres. Dutra, km 298, Bairro 27537-000 - Resende-RJ, Brasil, renan.nora@hotmail.com, glenio.barros@gmail.com, nilo.samp@terra.com.br.

${ }^{2}$ Universidade Estadual Paulista /Faculdade de Engenharia de Guaratinguetá, Avenida Dr. Ariberto Pereira da Cunha, 333, Bairro - 12244-000 - Guaratinguetá-SP, Brasil, jmottareis@gmail.com, otavio.oliveira@unesp.br.

Resumo - O ambiente industrial é atormentado por locais de trabalho pouco higiênicos, riscos à saúde e segurança, desperdício, baixa eficiência e eficácia e pessoal desmotivado, com o intuito de resolver e prevenir esses problemas o presente trabalho trata da implementação da ferramenta $5 \mathrm{~s}$ em uma microempresa no interior do estado do Rio de Janeiro com a finalidade de melhorar o ambiente organizacional, elevar a sua qualidade de serviços e produtividade, bem como promover um ambiente de cooperação entre seus colaboradores, tornando o local de trabalho harmonioso, e funcional, facilitando a realização de tarefas básicas, necessárias para o bom desempenho da empresa. Este trabalho teve por objetivo implementar o programa de qualidade $5 \mathrm{~s}$, para melhorar a qualidade de seus serviços.

Palavras-chave: Gestão da Qualidade, Melhoria Contínua, Gestão do Ambiente, $5 S$.

Área do Conhecimento: Engenharias. Engenharia de Produção.

\section{Introdução}

O ambiente industrial é atormentado por locais de trabalho pouco higiênicos, riscos à saúde e segurança, desperdício, baixa eficiência e eficácia e pessoal desmotivado. O impacto desses fatores causou um declínio na viabilidade econômica de muitas indústrias e leva ao fechamento organizações. Em vista disso, foram realizados estudos de caso em organizações para determinar a situação atual e determinar os efeitos da implementação dos princípios dos 5s (RAMDASS, 2015). Uma das ferramentas de programas de qualidade é o $5 S$ que tem como finalidade construir um ambiente de trabalho saudável, agradável e acolhedor para as pessoas e para isso acontecer é preciso que todos na empresa tenham consciência da necessidade de se trabalhar em equipe, ter respeito com as pessoas, ter responsabilidade, organização, empenho, satisfação e eficiência no trabalho (JACA et al., 2014).

Para a implementação do programa $5 S$ faz-se necessário perseverança, determinação e esforços constantes. O programa pode e deve levar em conta as necessidades de cada empresa e sua cultura local. Cada passo de sua implantação, tem que ser bem explicado para um claro entendimento do programa, não só com relação a sua execução, mas também na importância da mudança comportamental das pessoas (LIXIA; BO, 2008).

O programa $5 \mathrm{~S}$ foi desenvolvido como conduta para reduzir o desperdício, eliminar as perdas e otimizar a produtividade e qualidade. A prática dos $5 \mathrm{~s}$ tem como finalidade incorporar valores fundamentais como limpeza, organização e disciplina no ambiente de trabalho, possibilitando também uma mudança cultural na organização (GOH, 2015; GUPTA; JAIN, 2015). Dessa maneira, promovese um ambiente de trabalho sustentável e eficiente por meio de cinco termos em japonês que se traduzem em: Seiri - Senso de Utilização; Seiton - Senso de Organização; Seiso - Senso de Limpeza; Seiketsu - Senso de Padronização e Saúde; Shitsuke - Senso de Disciplina (JIMÉNEZ et al., 2015).

Este programa de qualidade é capaz de promover grandes transformações no humor das pessoas, no ambiente de trabalho, na maneira de conduzir atividades rotineiras e principalmente nas atitudes dos envolvidos no programa. É uma prática muito simples e pode ser implantada em qualquer lugar, organizações públicas e privadas, associações, escolas, igrejas, desde que haja esforço e comprometimento de todos (LIXIA; BO, 2008; RAMDASS, 2015). 
Diante de todos os benefícios que o $5 S$ proporciona a programas de qualidade, busca-se respostas consistentes para a seguinte questão: Como implementar com sucesso um programa de 5S dentro de microempresa. Para essa resolução, o presente trabalho tem como objetivo implementar o programa de qualidade $5 \mathrm{~s}$, para melhorar a qualidade de seus serviços. Este trabalho está organizado em sete seções, composto por: introdução, método de pesquisa, resultados, discussões, conclusão, agradecimentos e referências.

\section{Metodologia}

Este trabalho pode ser classificado de natureza aplicada. No que diz respeito aos objetivos desta pesquisa, ela pode ser descritiva e exploratória. Descritiva porque permite descrever as características do fenômeno observado (KOTHARI; GARG, 2019). Quanto à abordagem do problema, ela pode ser qualitativa, pois tem caráter exploratório e permite a compreensão de um fenômeno e a contribuição para a sua mudança, com foco os processos do objeto de estudo (MIGUEL, 2018).

Em relação aos procedimentos de pesquisa, foi o estudo bibliográfico e a pesquisa-ação e o estudo bibliográfico. O estudo bibliográfico está baseado numa pesquisa feitas por meio de informações já elaborados como: livros, revistas, jornais, documentos e artigos científicos. $\mathrm{Na}$ pesquisa-ação, o pesquisador está envolvido na faz parte do trabalho, ele observa e interfere no trabalho juntamente com outros participantes na busca de soluções (GIL, 2019).

Os procedimentos da pesquisa-ação deste trabalho foram divididos em 4 passo. O primeiro passo dado na empresa, foi a observação in loco, realizar a separação dos materiais necessários dos

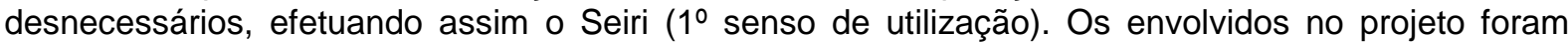
juntando em sacos plásticos todo objeto que era inútil, isto é, foram retirando de armários, gavetas, mesas, cestas, caixas tudo que não tinham mais utilidade, foram fazendo pilhas de sacos e coletivamente pensaram no destino adequado desse material, após classificação (doação, reciclagem, lixo). O segundo passo foi entender a necessidade de ordenar e identificar os materiais efetuando assim o Seiton ( $2^{\circ}$ senso de utilização). O grupo confeccionou etiquetas, utilizou caixas bem práticas para identificação dos materiais e etc. Arrumaram os materiais, objetos (como retalhos, linhas, ferramentas de agulhas, panos), de maneira funcional possibilitando o acesso rápido e fácil. Todos esses foram separados estrategicamente por função, cor, tamanho, frequência de uso e quantidade, entendendo assim como é imprescindível as pessoas serem organizadas, principalmente em uma empresa, pois isto facilita a vida, bem como gera uma maior produtividade. O terceiro passo, foi para todos na empresa, uma etapa bem cansativa, pois chegou o momento da limpeza, estabelecendo nesta etapa o compromisso coletivo de sua manutenção. Esta etapa é conhecida como Seiso (senso de limpeza) evitar sujar e manter a limpeza do dia a dia. Cada funcionário ficou responsável pela limpeza de um local, realizando todos uma faxina geral, atacando as fontes de sujeira inclusive nos locais de difícil acesso e visibilidade.

O quarto passo promoveu a consciência coletiva da importância de se manter os três primeiros "s" no dia a dia. Esta etapa é o Seiketsu (senso de padronização). Neste momento é definido um padrão de organização, limpeza que a empresa deseja e precisa ter e este padrão deve ser mantido e acompanhado pela equipe de trabalho na empresa e cobrado posteriormente. Padronizou-se também as formas de pagamento doa clientes, foi estabelecido o prazo para o pagamento das contas dos clientes, tipo de desconto dado nos pagamentos à vista e estabeleceu-se também a data máxima de retirada de produtos pelos clientes.

\section{Resultados}

Estabeleceu-se de início um comparativo do antes e depois da implantação dos $5 \mathrm{~s}$ com o objetivo de avaliar o trabalho realizado, valorizar o esforço/trabalho de todos os envolvidos. Motivar os colaboradores na manutenção do programa 5 s e principalmente fazer com que todos (diretoria e funcionários) acreditem que esta ferramenta do $5 \mathrm{~s}$ potencializa as atividades, melhora a qualidade dos serviços e produtos e promove significativas mudanças comportamentais nas pessoas.

A Figura 1 mostra de forma bem clara 0 antes e depois da organização. Antes as linhas eram colocadas em uma caixa dificultando a procura e consequentemente sua utilização. 


\section{XXIVINIC XX,EPG IIICONPAT XIVINICI XINID \\ GOC ZDADEF E E E E

Figura 1- Antes e depois da implementação do 5 S no estoque.
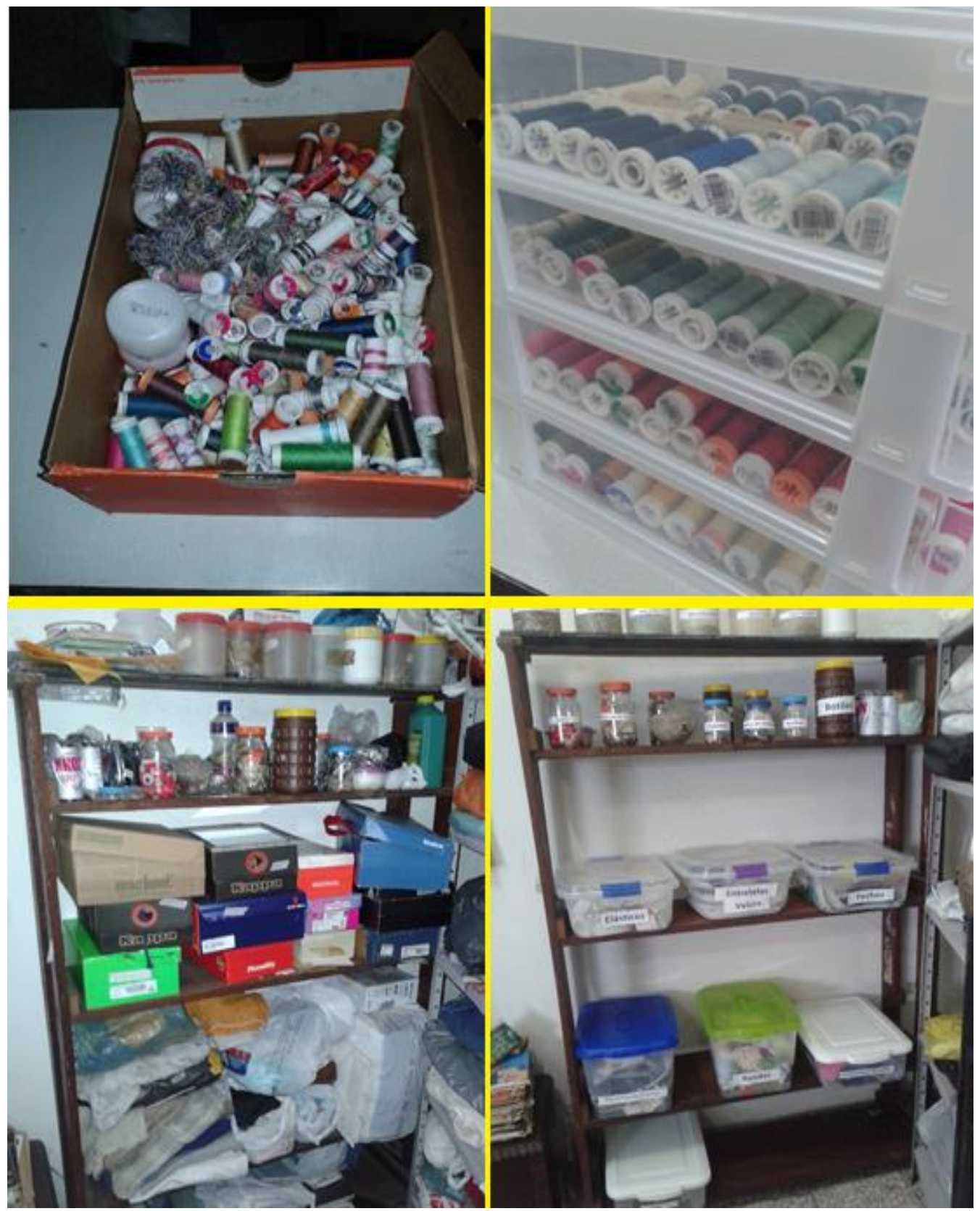

Fonte: Próprios Autores (2020).

A figura 2 mostra o antes e depois de materiais diversos, utilizados por todos na empresa colocados num armário sem nenhum critério, isto é, colocados em caixa de papelão sem identificação, sem nenhum tipo de arrumação, o que dificultava o trabalho pois o acesso era difícil e gastava muito tempo na procura. Após a ordenação os materiais foram separados de acordo com sua função colocados em caixas transparentes e com identificação, o que trouxe praticidade e eficiência na utilização dos mesmos por todos. 


\section{XXIVINIC XX,EPG IIICONPAT XIVINICI XINID \\ GOQIEDADE

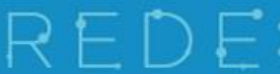

Figura 2- Antes e depois da implementação do 5 S na linha de produção.

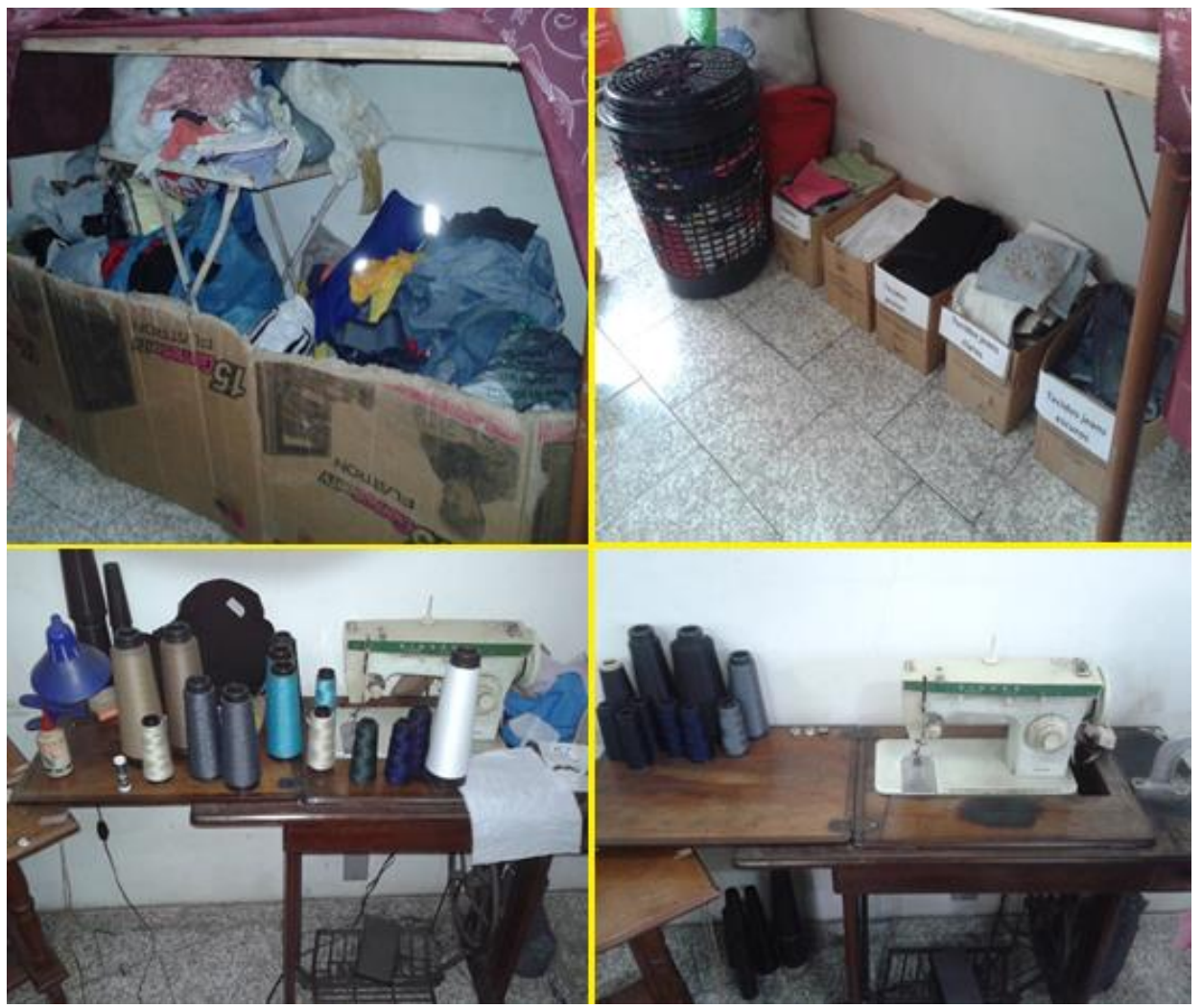

Fonte: Próprios Autores (2020).

\section{Discussões}

Depois da implementação do 5S, identificou-se que as linhas foram organizadas conforme tons de cor, facilitando a visualização e permitindo maior eficiência no uso. Mostra também o antes e depois de materiais diversos, utilizados por todos na empresa colocados num armário sem nenhum critério, isto é, colocados em caixa de papelão sem identificação, sem nenhum tipo de arrumação, o que dificultava o trabalho pois o acesso era difícil e gastava muito tempo na procura. Após a ordenação os materiais foram separados de acordo com sua função colocados em caixas transparentes e com identificação, o que trouxe praticidade e eficiência na utilização dos mesmos por todos.

Identifica-se que os funcionários eram acumuladores de objetos, isto é, juntavam vários materiais inúteis embaixo da mesa, guardados em caixas, após a arrumação pôde-se fazer o descarte de tudo aquilo que era desnecessário à empresa, destinando adequadamente o material descartado. Identificou-se também um grande desperdício de materiais como por exemplo de alfinetes e agulhas que se perdiam facilmente, daí a ideia de se utilizar catadores de imãs para recuperação dos mesmos. Neste identificou-se a quantidade de materiais acumulados sem utilidade, que prejudicavam as atividades na empresa e consequentemente o trabalho individual de todos os funcionários.

$\mathrm{Na}$ medida em que as mudanças iam acontecendo, era visível em cada funcionário o orgulho da missão comprida e o reconhecimento das melhorias obtidas, isto é, reconhecendo que o local de trabalho estava bem mais agradável e funcional, e que o programa $5 \mathrm{~s}$ tem realmente grande relevância no lado profissional e pessoal.

O quinto e último passo da implantação dos 5 s na empresa é o Shitsuke (senso de autodisciplina) que é cumprir rigorosamente o que foi estabelecido: manter os sensos anteriores com muita determinação sem haver necessidade de constantes cobranças. 


\section{Conclusão}

Conclui-se que a microempresa obteve êxito na implantação do programa de qualidade $5 \mathrm{~s}$, seu ambiente de trabalho tornou-se mais seguro, harmonioso e agradável, seus produtos e serviços deram um salto na qualidade, seus colaboradores mudaram de comportamento, apresentando no trabalho e na vida pessoal bons hábitos de limpeza, organização e higiene.

A principal característica do programa 5s é a simplicidade, entretanto, para que este não se perca com o tempo é preciso que ele seja adaptado e praticado com muito rigor, determinação e vontade de todos da empresa. Entenda-se que todo o programa ligado ao processo tem como base de sustentação a "educação", pois sem este alicerce, qualquer estratégia de programa de qualidade fracassará e não será como deve ser, incorporado e adaptado à cultura de cada organização e de cada indivíduo. Fatores que limitarem a pesquisa foram o pequeno porte da organização utilizada na pesquisa-ação e os recursos limitados para maiores mudanças, recomenda-se a implementação em uma organização de confecção de grande porte.

\section{Agradecimentos}

Este trabalho foi financiado em parte pela Coordenação de Aperfeiçoamento de Pessoal de Nível Superior - Brasil (CAPES) - Código Financeiro 001 e pelo CNPq - Conselho Nacional de Desenvolvimento Científico e Tecnológico - (312894 / 2017-1) para apoio financeiro.

\section{Referências}

GIL, A. C. Métodos e Técnicas de Pesquisa Social. 7. ed. São Paulo: Atlas, 2019.

$\mathrm{GOH}, \mathrm{T}$. N. Emerging Megatrends in Quality Engineering and the "New 5S" Response. Quality Engineering, v. 27, n. 4, p. 450-460, 2 out. 2015.

GUPTA, S.; JAIN, S. K. An application of 5 S concept to organize the workplace at a scientific instruments manufacturing company. International Journal of Lean Six Sigma, v. 6, n. 1, p. 73-88, 2 mar. 2015.

JACA, C. et al. Learning 5S principles from Japanese best practitioners: case studies of five manufacturing companies. International Journal of Production Research, v. 52 , n. 15 , p. $4574-$ 4586, 3 ago. 2014.

JIMÉNEZ, M. et al. 5S methodology implementation in the laboratories of an industrial engineering university school. Safety Science, v. 78, p. 163-172, out. 2015.

KOTHARI, C. R.; GARG, G. Research methodology methods and techniques. $4^{\circ}$ ed. Nova Deli: New Age International, 2019.

LIXIA, C.; BO, M. How to Make 5S as a Culture in Chinese Enterprises. 2008 International Conference on Information Management, Innovation Management and Industrial Engineering. Anais...IEEE, dez. 2008Disponível em: <http://ieeexplore.ieee.org/document/4737762/>

MIGUEL, P. A. C. Metodologia de pesquisa para engenharia de produção e gestão de operações. $3^{\circ}$ ed. Rio de Janeiro: Elsevier, 2018.

RAMDASS, K. Integrating 5S principles with process improvement: A case study. 2015 Portland International Conference on Management of Engineering and Technology (PICMET). Anais...IEEE, ago. 2015Disponível em: <http://ieeexplore.ieee.org/document/7273045/> 